\title{
Comparison of postoperative sore throat following laryngoscopy conducted by Miller and Macintosh laryngoscope blades
}

\author{
Khosro Barkhordari, Farhad Etezadi, Reza Shariat Moharari, Mohammad Reza Khajavi
}

Tehran University of Medical Sciences, Sina Hospital, Tehran, Iran; ${ }^{*}$ Corresponding author: khajavim@tums.ac.ir

Received 6 January 2011; revised 1 June 2011; accepted 15 June 2011.

\begin{abstract}
BACKGROUND: Post operative sore throat (PST) is one of the most common complaints after tracheal intubation. In this study we compared the effects of curved and straight laryngoscope blades on severity and incidence of PST. METHOD: In this prospective randomized clinical trial we evaluated incidence and severity of PST in 147 ASA physical status I-II, aged $18-62$ y (group Miller, $n=71$ ), (group Macintosh, $n=76$ ) following intubation with Miller and Macintosh laryngoscope blades by using Visual Analog Scale (VAS). RESULTS: The overall incidence of PST in our study was $35.4 \%$ (Macintosh group = $39.5 \%$ and in Miller group $=31 \%$ and $P=0.829$ ). The incidence of PST was not statistically different between two kinds of laryngoscope blades and the mean rank of pain score was not statistically different in recovery room and up to 48 hours after surgery. CONCLUSIONS: Our study showed these types of laryngoscope blade had not association with incidence and severity of PST.
\end{abstract}

Keywords: Post Operative Sore Throat; Tracheal Incubation; Laryngoscope Blades

\section{INTRODUCTION}

Post operative sore throat (PST) is one of the most frequent complaints after tracheal intubation and its incidence varies between 14\% - 50\% [1-4]. Mucosal injury, stretch of ligaments and muscles of throat, prolonged surgery, changing position of patients during surgery have been implicated in the pathogenesis of PST [4].

Chandler's study showed that pressure trauma is very important to induce PST and he found an association between mechanical forces and PST [4].

Our hypothesis was that straight blade (Miller) generates less pressure on pharyngeal wall, muscles and liga- ments of pharynx than curved blade (Macintosh). Hastings et al showed that the use of Miller laryngoscope blade required less force and head extension than Macintosh one [5]. We didn't find any study comparing severity of pain produced by these two common blades used for laryngoscopy.

The aim of our study was to compare the incidence and severity of PST with Macintosh and Miller laryngoscope blades during normal intubating attempts.

\section{METHODS}

After Institutional Ethics Committee approval, written informed consent was obtained for all patients. We prospectively studied 147 consecutive adult patients (18 64 years old) with ASA physical status I-II receiving general anesthesia with tracheal intubation. Using a computer generated sequence of numbers, patients were randomly allocated to be intubated using either a straight blade laryngoscope $(n=71)$ or a curved blade, $(n=76)$.

Failure to tracheal intubation in the first attempt, positive history of sore throat, use of NSAIDS, head and neck surgery, smoking, Mallampati class greater than 2 were our exclusions criteria. After establishing IV access and use of standard monitoring, midazolam $0.05 \mathrm{mg} / \mathrm{kg}$, fentanyl $2 \mu \mathrm{g} / \mathrm{kg}$ injected as premedication, thiopental $\mathrm{Na} 5 \mathrm{mg} / \mathrm{kg}$, and atracurium $0.4 \mathrm{mg} / \mathrm{kg}$ were used for induction of anesthesia. An anesthesiologist with three years of continuous practice performed all endotracheal intubation gently. Size of tracheal tubes were adjusted for age and body size of patients, and miller no 2 and Macintosh no 3 blades were used. Endotracheal tubes (ETT) were lubricated with sterile water. ETT cuffs were inflated at the safe occlusive volume so initial Cuff pressure was fixed at $20 \mathrm{~cm} \mathrm{H}_{2} \mathrm{O}$ (Mallinckrodt, Seelscherf 1, Germany). Anesthesia was maintained by: air/ $\mathrm{N}_{2} \mathrm{O}(50 \% / 50 \%)$, isoflurane (1\% to $\left.1.2 \%\right)$ and intermittent injection of fentanyl as was necessary.

When tracheal extubation criteria were met (return of neuromuscular function confirmed using train-of-four 
peripheral nerve stimulation, ability to follow verbal commands, regular spontaneous ventilation), tracheal extubation was performed just after gentle suctioning at the discretion of anesthesiologist who was a member of anesthesia team. Another anesthesiologist who was blinded to the study evaluated the PST with a Visual Analog Scale (VAS, 0 - 10 score) in the postoperative period (at $0,3,6,12,24$ and 48 hours after surgery). Sample-size was calculated based on our pilot study with 70 patients. In order to permit 5\% of type 1 error enrollment of 73 patients in each group was required. Demographic characteristics and incidence of pain in both groups were com- pared by using chi-square and Student's $t$-test. VAS scores were analyzed using Wilcoxon rank sum test. Medians and their confidence intervals were calculated using binomial interpretation. Statistical significance was defined as $\mathrm{P}<0.05$. Data were analyzed using SPSS version 13 and Intercooled STATA version 9.1.

\section{RESULTS}

One Hundred Forty Seven patients were enrolled in the study. Two cases in Miller group were excluded from the study because first intubation attempt was failed. At the baseline, there were no statistically significant differences between groups regarding sex, age, Mallampatti class, and ASA class and operation time between two groups (Table 1). The overall incidence of PST in our study was 35.4\% (Macintosh group $=39.5 \%$ and in Miller group $=31 \%$ and $\mathrm{P}=0.829$ ) and the highest mean VAS score was observed at third post operative hour in both groups (Figure 1).

The assumption for performing parametric test did not met; therefore we used Wilcox, rank sum test to compare VAS scores in the study groups. The assumption for per-

Table 1. Patient characteristics and demographic data.

\begin{tabular}{cccc}
\hline & $\begin{array}{c}\text { Group A: Macintosh } \\
\text { blade (n=76) }\end{array}$ & $\begin{array}{c}\text { Group B: Miller } \\
\text { blade (n=71) }\end{array}$ & P value \\
\hline Sex; n (\%) & $26(34.2 \%)$ & $19(27.7 \%)$ & $\mathrm{P}=0.33$ \\
Male & $50(66 \%)$ & $52(73.2 \%)$ & \\
Female & & & \\
$\begin{array}{c}\text { Mallampatti } \\
\text { class n (\%) }\end{array}$ & $74(97.3 \%)$ & $70(98.6 \%)$ & $\mathrm{P}=0.33$ \\
I & $2(2.7 \%)$ & $1(1.4 \%)$ & \\
II & & & \\
ASA class & & $69(97 \%)$ & $\mathrm{P}=0.74$ \\
I & $51(93.4 \%)$ & $2(2.8 \%)$ & \\
II & $33.4 \pm 12.8$ & $29.6 \pm 10.4$ & $\mathrm{P}=0.47$ \\
$\begin{array}{c}\text { Mean Age (yr) } \\
\text { Operation time } \\
\text { (min) }\end{array}$ & $52 \pm 9.7$ & $51.9 \pm 8.7$ & $\mathrm{P}=0.829$ \\
\hline
\end{tabular}

ASA: American Society of Anesthesiologists.

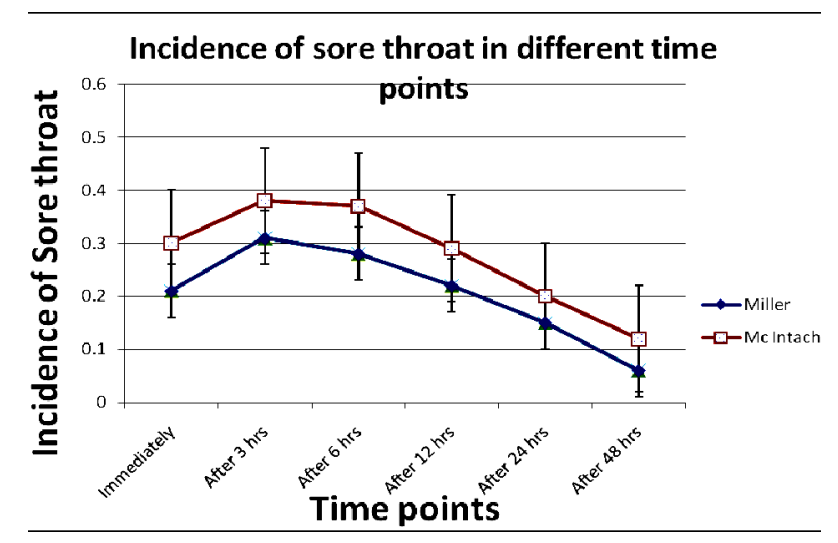

Figure 1. Incidence of sore throat in different time after operation.

forming parametric test did not met; therefore we used Wilcox, rank sum test to compare VAS scores in the study groups.

\section{DISCUSSION}

In our country, curved blade laryngoscope are more commonly used than straight blades especially in our hospital, because the laryngoscopic views obtained with curved blades are better than straight blades [10]. However, there are many studies regarding severity and higher incidence of PST in patients who were intubated with curved blades [6-9]. Skills of intubator, history of smoking, lung disease, and pressure of cuff and operation time have been implicated to be the factors which are associated with PST [3,6-9]. Chandler's study showed that mechanical trauma is an important factor in pathogenesis of PST and he found a positive assosiation between mechanical forces and PST (they studied on mechanical models) [4]. We didn’t find any study in literature for comparing incidence and severity of PST with these two kinds of laryngoscope blades during tracheal intubation. However, One study showed that force, torque and head extension were $30 \%$ less with Miller blade compared to Macintosh blade [5].

Our impression was that mechanical trauma plays more important role in producing PST than other probable factors. We thought that reducing stretch forces during intubation by using straight blade may decrease the rate of PST. But our study showed that PST rate in recovery room and during first 48 hours after surgery was not statistically different between Macintosh and Miller blade. Our study has several limitations. One of those was medications that we had to give to the patients because of surgical pain in postoperative period. We administered equivalent doses of morphine $0.1 \mathrm{mg} / \mathrm{kg}$ for reducing postoperative surgical pain to both groups of the patients. Another limitation was difficulty in ob- 
taining VAS score immediately after awakening from anesthesia in some patients because of residual effect of anesthetics. Other limitation of our study is enrollment of only class 1 airway patients and excluding patients with mallampatti class 3 and 4, therefore we suggest new studies for finding probable association between difficult intubation and occurrence of PST.

In conclusion, we didn't find statistically significant differences in the incidence and severity of PST between curved and straight laryngoscope blades during uncomplicated attempts of intubation.

\section{REFERENCES}

[1] Al-Qahtani, A.S. and Messahel, F.M. (2005) Quality improvement in anesthetic practice: Incidence of sore throat after using small tracheal tube. Middle East Journal of Anesthesiology, 18, 179-183.

[2] Christensen, A.M., Willemoes-Larsen, H., Lundby, L. and Jakobsen, K.B. (1994) Postoperative throat complaints after tracheal intubation. British Journal of Anaesthesia, 73, 786-787. doi:10.1093/bja/73.6.786

[3] Biro, P., Seifert, B. and Pasch, T. (2005) Complaints of sore throat after tracheal intubation: A prospective evaluation. European Journal of Anaesthesiology, 22, 307-311. doi:10.1017/S0265021505000529

[4] Chandler, M. (2002) Tracheal intubation and sore throat: A mechanical explanation. Anaesthesia, 57, 155-161. doi:10.1046/j.1365-2044.2002.02329.x

[5] Hastings, R.H., Hon, E.D., Nghiem, C. and Wahrenbrock, E.A. (1996) Force and torque vary between laryngoscopists and laryngoscope blades. Anesthesia \& Analgesia, 82, 462-468.

[6] Higgins, P.P., Chung, F. and Mezei, G. (2002) Postoperative sore throat after ambulatory surgery. British Journal of Anaesthesia, 88, 582-584. doi:10.1093/bja/88.4.582

[7] Takekawa, K., Yoshimi, S. and Kinoshita, Y. (2006) Effects of intravenous lidocaine prior to intubation on postoperative airway symptoms. Journal of Anesthesia, 20, 44-47. doi:10.1007/s00540-005-0363-8

[8] Hara, K. and Maruyama, K. (2005) Effect of additives in lidocaine spray on postoperative sore throat, hoarseness and dysphagia after total intravenous anaesthesia. Acta Anaesthesiologica Scandinavica, 49, 463-467. doi:10.1111/j.1399-6576.2005.00632.x

[9] Estebe, J.P., Gentili, M., Le Corre, P., Dollo, G., Chevanne, F. and Ecoffey, C. (2005) Alkalinization of intracuff lidocaine: Efficacy and safety. Anesthesia \& Analgesia, 101, 1536-1541. doi:10.1213/01.ANE.0000180995.24211.89

[10] Arino, J.J., Velasco, J.M., Gasco, C. and LopezTimoneda F. (2003) Straight blades improve visualization of the larynx while curved blades increase ease of intubation: a comparison of the Macintosh, Miller, McCoy, Belscope and Lee-Fiber view blades. Canadian Journal of Anesthesia, 50, 501-506. doi:10.1007/BF03021064 